\title{
Influence of Ethical Leadership on Employees' Innovative Behavior: The Role of Organization-Based Self-Esteem and Flexible Human Resource Management
}

\author{
Qiuxiang Wen ${ }^{1}$, Yingxuan $\mathrm{Wu}^{2, *}$ and Jing Long ${ }^{1, *}$ \\ 1 School of Business, Nanjing University, Gulou District, Nanjing 210093, China; qx_wenaut@163.com \\ 2 Development Institute of Jiangbei New Area, School of Business, Nanjing University of Information Science \& \\ Technology, Pukou District, Nanjing 210044, China \\ * Correspondence: yingxuanwunju@163.com (Y.W.); longjing@nju.edu.cn (J.L.)
}

Citation: Wen, Q.; Wu, Y.; Long, J. Influence of Ethical Leadership on Employees' Innovative Behavior: The Role of Organization-Based Self-Esteem and Flexible Human Resource Management. Sustainability 2021, 13, 1359. https://doi.org/ $10.3390 /$ su13031359

Academic Editor:

Katarzyna Szopik-Depczyńska

Received: 5 December 2020

Accepted: 25 January 2021

Published: 28 January 2021

Publisher's Note: MDPI stays neutral with regard to jurisdictional claims in published maps and institutional affiliations.

Copyright: (c) 2021 by the authors. Licensee MDPI, Basel, Switzerland. This article is an open access article distributed under the terms and conditions of the Creative Commons Attribution (CC BY) license (https:// creativecommons.org/licenses/by/ $4.0 /)$.

\begin{abstract}
Employees' innovative behavior is a vital source for promoting the sustainable survival and development of enterprises. Innovation is a complicated and high-risk mental process, where in each stage employees' innovative attitude and behavior will be affected by the varying behaviors of their direct leaders. Therefore, exploring the intricate relationship between leadership behavior and employees' innovative behavior is necessary. Based on social exchange theory, this study builds a cross-level moderation model to investigate the impact of ethical leadership on employees' innovative behavior and the mediating role of organization-based self-esteem and the moderating role of flexible human resource management. On the basis of a questionnaire survey of 146 supervisors and 365 subordinates in the mainland of China, the empirical results show that: (a) Ethical leadership positively affects employees' innovative behavior significantly; (b) Organization-based self-esteem has a partial mediating relationship between ethical leadership and employees' innovative behavior; and (c) flexible human resource management plays a positive moderating role in the relationship between organization-based self-esteem and employees' innovative behavior, and it also positively moderates the mediating effect of organization-based self-esteem on the relationship between ethical leadership and employees' innovative behavior. The findings reveal the internal mechanism and boundary condition of ethical leadership influencing employees' innovative behavior, which provide a reference for enterprises to encourage employees to innovate, and have important practical significance for employees to actively pursue innovative activities in the workplace.
\end{abstract}

Keywords: ethical leadership; organization-based self-esteem; employees' innovative behavior; flexible human resource management

\section{Introduction}

In an environment of volatility, uncertainty, complexity and ambiguity (VUCA), innovation became the key for enterprises to obtain a competitive advantage and maintain sustainable development [1]. Employee innovation is regarded as the core competence of the enterprises, and the innovative thinking and innovative activities of individual employees are the foundation of sustainable innovation [2]. Thus, how to stimulate employees' innovative behavior remains the focus of the theoretical and practical fields. Prior studies have identified various predictors of employees' innovative behavior and generally believe that effective leadership behavior in organizations is one of the important influencing factors that promote employee innovation [3,4]. Organizational leaders are prominent actors who can cultivate employees' innovative behavior in the workplace, thus bringing new changes to their elusive situation [5].

Although previous academic studies focused on the relationship between charismatic, authentic and transformational leadership and employees' innovative behavior in the organization [6,7], studies on the relationship between ethical leadership and employees' 
innovative behavior remain limited. Generally, an ethical leader can be understood from two perspectives: a moral person and a moral manager [8]. Hence, research on ethical leadership mostly focuses on the moral aspects and connects ethical leadership with employees' organizational citizenship behavior [9], moral identity [10] and other moral behaviors, as well as their counterproductive behavior [11], deviant behavior [12] and other immoral behaviors. However, scholars pay less attention to the innovative work behavior that makes a great contribution to organizational innovation, development and survival [13]. When ethical leaders care for employees' self-development, provide innovation resources, tolerate employees' innovation failure and actively authorize employees to implement innovation, employees usually show more innovative behaviors [14]. Some scholars investigated the underlying mechanism from the aspects of intrinsic motivation [13], psychological capital [14,15], psychological security [16] and knowledge sharing [17] in organizations. Although some valuable conclusions have been drawn from these studies, there remains space for further exploration. Social exchange theory regards the ethical influence of leaders on subordinates as a process of reciprocity [18]. Ethical leadership emphasizes how to deal with the interaction between leaders and employees in the organization. Specifically speaking, ethical leadership protects the employees' rights and attaches importance to equality, freedom, respect and other basic human rights in interpersonal interaction [19]. Therefore, employees can realize their own value from work, that is, they have higher organization-based self-esteem (OBSE), which produces a strong sense of responsibility of sincere return, and are willing to carry out more innovative activities for the organization. Accordingly, we relied on social exchange theory (SET) to explain the internal mechanism linking ethical leadership and employees' innovative behavior.

In addition, employees' self-evaluation in organizations (OBSE) may influence their innovative behavior in different situations distinctly. Particularly, the organization situation in which an individual is located will significantly promote (or hinder) the transformation of the individual's cognitive, emotional and other psychological factors into specific behaviors [20]. Previous studies focused on the contextual effects of OBSE on employees' innovative behavior from the perspectives of labor rights protection, organizational innovation reward and organizational support [21,22]. In recent years, with the increasingly fierce market competition and the importance of innovative development, to mobilize the innovation enthusiasm of employees, many organizations have adopted a flexible management in terms of coordination, function and resources in human resource management practice [23]. Thus, whether or not flexible human resource management (FHRM) will affect organization-based self-esteem and employees' innovative behavior, as well as the transformation process from ethical leadership to employees' innovation behavior, remains unanswered. Therefore, studying this issue is of certain theoretical and practical value.

Ultimately, this study will focus on the two issues of "when and how ethical leadership can promote employees' innovative behavior". By studying the mediating mechanism of organization-based self-esteem and the moderating role of flexible human resource management, it can not only exert ethical leadership more effectively, but also provide more valuable theoretical guidance and practical reference for ethical leadership on how to effectively motivate employees to innovate.

\section{Theoretical Background and Research Hypotheses}

\subsection{Ethical Leadership and Employees' Innovative Behavior}

With the frequent outbreak of enterprise scandals worldwide, people pay attention to the ethics and social responsibility of enterprises [24], and hence leaders are more than ever required to behave ethically. Consequently, ethical leadership has been widely valued by both academics and practitioners in the past decade. Many scholars have investigated its effect on employees' work attitudes and behavior and found that ethical leadership could predict employees' job satisfaction, organization commitment, voice behavior and organizational citizenship behavior effectively [8]. Some scholars discussed the relationship between ethical leadership and employees' innovative behavior [16,25]. 
According to Brown et al., ethical leadership refers to demonstrating a normatively appropriate conduct through personal actions and interpersonal relationships, and the promotion of such conduct to followers through two-way communication, reinforcement and decision making [8]. Generally, an ethical leader can be understood from two perspectives: a moral person and a moral manager. As a moral person, an ethical leader is honest, moral, trustworthy, caring and justicial, and exercises these qualities in his daily work and life $[8,26,27]$. As a moral manager, an ethical leader is expected to influence subordinates' attitudes and behaviors through ethical leadership behavior, such as emphasizing integrity, respecting subordinates, supporting their development, improving the importance and autonomy of their work and making fair and reasonable decisions [13,28].

Innovative behavior is a series of behaviors in which employees generate new ideas in the work process and strive to put them into practice, including extensively seeking and discovering new opportunities and solutions, promoting the generation of ideas, striving to obtain support from sponsors, advancing the generated ideas and carrying out feasibility tests $[29,30]$. In this ever-changing era, enterprises must adapt to the external environment through continuous innovation, and the innovative behavior of employees is crucial to the survival of enterprises and the maintenance of a sustainable competitive advantage [31-33]. Given that innovation is a complex process with high risks, positive leadership behavior is considered a central factor in promoting employee innovation [34]. According to social exchange theory, leaders and subordinates exert their benefits through a social exchange relationship [31]. When employees perceive the respect, care, support and motivation from the leader, on the basis of the principle of reciprocity, they usually respond with positive behaviors. This study holds that the impact of ethical leadership on employees' innovative behavior is mainly reflected in the following aspects: (1) Ethical leaders emphasize that the work should be beneficial to others, the group, the organization and the whole society, so that subordinates will perceive the significance of their work and are willing to take pains in generating new ideas and strive to implement them to contribute to the organizational goals [8,35]; (2) An ethical leader has integrity, respects his subordinates, pays attention to the subordinates' growth and provides various opportunities to improve the subordinates' knowledge and skills. As a result, the employees will be equipped with the abilities, knowledge and skills to innovate, which will encourage them to implement innovative behaviors in the work place; (3) An ethical leader will pay attention to the role of his subordinates in decision making and give them work autonomy, such as the freedom and discretion to set their own schedule, so that they have control over their tasks [36], and less restrictions in the proposal, promotion and implementation of innovative ideas, since a high work autonomy will promote employees' innovative behavior [37]; (4) When subordinates fail in innovation, ethical leaders can evaluate employees' efforts fairly and provide them with a relaxed atmosphere of trial and error to encourage them to set aside the fear of punishment and exhibit innovative behavior. Previous researchers also verified that ethical leadership promotes employees' innovative behavior [14,15]. Hence, we propose the following hypothesis:

Hypothesis 1 (H1). Ethical leadership positively influences employees' innovative behavior.

\subsection{Ethical Leadership and Organization-Based Self-Esteem of Employees}

Some scholars proposed that employees' self-concept determines the influence of leadership on employees [3], but there are very few studies on how leaders affect employees' attitude and behavior from the perspective of self-concept [38]. In the existing literature, the influence of ethical leadership on employees' innovative behavior from the perspective of organization-based self-esteem (OBSE) remains unexplored [9-11]. According to Chen and Aryee [39], as a dimension of self-evaluation in self-concept, OBSE reflects employees' evaluation of the importance of self-concept and competence, as well the extent to which people believe they are capable, significant and valuable [40]. On this basis, Pierce et al. proposed the concept of OBSE and defined it as the self-evaluation of individuals' per- 
ceived importance to the organization and their competence for organizational work [41]. Employees with a high OBSE believe they are competent for the work and that "I am valuable to the organization." OBSE is different from general self-esteem. It is a reflection of an individual's overall self-esteem in a specific organizational context, which is situational and changeable [42]. Existing studies have shown that OBSE is not only affected by individual characteristics, but also by the organization situation [43], such as leaders' trust, organizational support, workplace fairness, and so on, which will affect employees' evaluation of their own competence and value; and these factors, in turn, are influenced by the leadership style.

Ethical leaders are honest, considerate, respect and trust employees, and pursue fairness in the organization [15]. Their respect and trust will make employees feel that the organization or leaders attach importance to them and recognize their value. The perceived respect and support from leaders will affect their belief in themselves in the organizational environment, thus improving their OBSE [44]. In addition, ethical leaders provide various kinds of support and show consideration and concern for their subordinates through appropriate feedback and fair interaction, which will improve employees' assessment of their own value and competence in the organization [13]. Previous studies also confirmed the above viewpoints. For example, Brown et al. [8] believed that ethical leaders' integrity, fairness and emphasis on empowerment could stimulate employees to have a high level of OBSE. Zhang Yongjun also found that ethical leadership helps improve employees' organization-based self-esteem [11]. Ultimately, ethical leadership will make employees feel valuable, important, meaningful and sure of themselves in organizations, thus improving their OBSE. Accordingly, we propose the following hypothesis:

Hypothesis 2 (H2). Ethical leadership positively influences employees' organization-based self-esteem.

\subsection{The Mediating Effect of Organization-Based Self-Esteem}

In an organization, individuals' judgment of their own ability and value is the driving force to shape their positive attitudes and behaviors, which then leads to results beneficial to individuals and organizations [45]. Employees with high organization-based self-esteem (OBSE) usually have a high subjective efficacy and a very positive self-evaluation. This encourages them to achieve a high-level performance and positive behavior, such as voice behavior $[39,46]$. This study argues that employees' OBSE will positively affect their innovative behavior, which is mainly reflected in the following two aspects: on the one hand, employees with low OBSE often have low confidence in their competence and doubt whether they can put forward new valuable ideas and further implement them, thus reducing their innovative behavior. On the contrary, employees with high OBSE usually believe that they have high abilities and are competent for their work in the organization, so they are more willing to take risks and carry out innovative behavior. On the other hand, compared with employees with low OBSE, employees with high OBSE have a high evaluation of their value and importance in the organization. Especially in a collectivism-oriented society, individuals will actively associate their personal goals with organizational goals [21] and strive to promote the healthy development of the organization to maintain and strengthen their own importance in the organization. Given that innovation is crucial to the survival and development of an organization, despite the risk of trial and error in innovation, employees with high OBSE will still take risks to engage in innovative activities and behaviors beneficial to the organization to maintain their OBSE needs. Contrarily, employees with low OBSE often have difficulty in internalizing organizational goals as personal goals due to their self-perceived dispensable role in the organization, thus reducing the high-risk behavior of innovation [47]. Previous studies confirmed that OBSE has a positive effect on employee behavior [45], and employees with high OBSE are willing to take risks, trial and error, and engage in innovative activities [39].

According to the above discussion, ethical leadership respects and trusts employees in their work, supports their work and pursues justice and fairness in the organization to 
make employees feel that their work can be respected and recognized, which produces the feeling that they are important and valuable in the organization. This leads to a high self-evaluation with regard to competence, that is, to a high OBSE. In addition, employees perception of organizational competence and value will encourage them to take risks and contribute to the development of the organization, internalize the goals of the organization into their own goals and conduct innovative behavior to maintain and strengthen their high OBSE. In summary, ethical leadership can significantly improve employees' OBSE, and employees' OBSE will further encourage them to engage in innovative behavior, that is, ethical leadership will indirectly promote employees' innovative behavior through OBSE. In light of the mentioned explanations, we propose the following hypotheses:

Hypothesis 3 (H3). Organization-based self-esteem positively influences employees' innovative behavior.

Hypothesis 4 (H4). Organization-based self-esteem plays a mediating role in the relationship between ethical leadership and employees' innovative behavior.

\subsection{The Moderating Effect of Flexible Human Resource Management}

The increasingly fierce competition and environmental uncertainty urge the organizations to improve their flexibility to deal with the environment and conduct flexible management. Flexible human resource management (FHRM) refers to a management system in which an organization provides employees with a set of opportunities to choose when and how to work [48], including flexibility in coordination, functions and resources. The implementation of FHRM in enterprises helps improve employee engagement, job satisfaction and production efficiency [49]. With the change of external environment, more and more organizations realize that the improvement of individual productivity and the growth of the organization depend on skilled and motivated employees. In recent years, FHRM has shown an obvious upward trend in organizations [50]. Many studies also stress the importance of FHRM [48,51,52].

When employees have the opportunity to utilize flexibility, they can use resources to achieve job-related goals [53,54]. FHRM provides employees with opportunities, abilities and work motivation, which makes the workplace productive. Organization-based self-esteem (OBSE) enhances employees' perception of importance and competence in the organization and encourages them to engage in innovative behavior. When the organization's FHRM is low, employees will feel that their opportunities and abilities are restricted and their work engagement is reduced [54], thereby weakening the positive impact of OBSE on innovation behavior. Contrastingly, when the FHRM is high, it means that the organization provides high flexibility for employees regarding work coordination, functions and resources, to satisfy employees regarding their current work and improve their work commitment [51]. Thus, when employees perceive their importance and competence, they will engage in innovative behavior, which will improve the effect of OBSE on employees' innovative behavior. Thus, this study proposes the following hypothesis:

Hypothesis 5 (H5). FHRM positively moderates the relationship between organization-based self-esteem and employees' innovative behavior, such that the relationship is stronger when FHRM is high than when it is low.

According to the deduction process of the above hypothesis, we believe that flexible human resource management (FHRM) can also moderate the mediating effect of OBSE on ethical leadership and employees' innovative behavior. The main reason is that, on the one hand, when the organization's FHRM is low, it will hinder the ethical leadership's positive influence on employees' innovative behavior through OBSE. Specifically, employees with high OBSE raised by ethical leadership will be encouraged to maintain and strengthen their high self-evaluation and OBSE. However, when the FHRM is low, the opportunities and abilities of employees will be limited, and thus they will not pursue innovative behavior. Meanwhile, in organizations with low FHRM, employees with weak OBSE due to low 
ethical leadership will also be less engaged in innovative behavior because of the lack of the need to strengthen the belief in OBSE. Thus, the low FHRM adopted by the organization will promote the employees who are based on the OBSE produced by different degrees of ethical leadership to show low innovative behavior. Contrarily, when the FHRM is high, employees have a high flexibility in the organization, which will improve their job satisfaction and work engagement and promote the ethical leadership's positive influence on employees' innovative behavior through OBSE. Specifically, high OBSE formed by ethical leadership makes employees generate and strengthen the need for self-evaluation. When the organization has high FHRM, employees' ability can be effectively used, and innovative behavior can be pursued. However, for employees with low OBSE formed by low-level ethical leadership, even if the organization has high FHRM, they will not be led to innovate due to the lack of the demand to enhance OBSE. Fundamentally, FHRM will encourage employees on the basis of the OBSE produced by different levels of ethical leadership to exhibit different innovative behaviors. On the basis of the above analysis, we propose the following hypothesis:

Hypothesis 6 (H6). FHRM moderates the mediating effect of organization-based self-esteem on the relationship between ethical leadership and employees' innovative behavior.

Ultimately, this study proposes the research model shown in Figure 1.

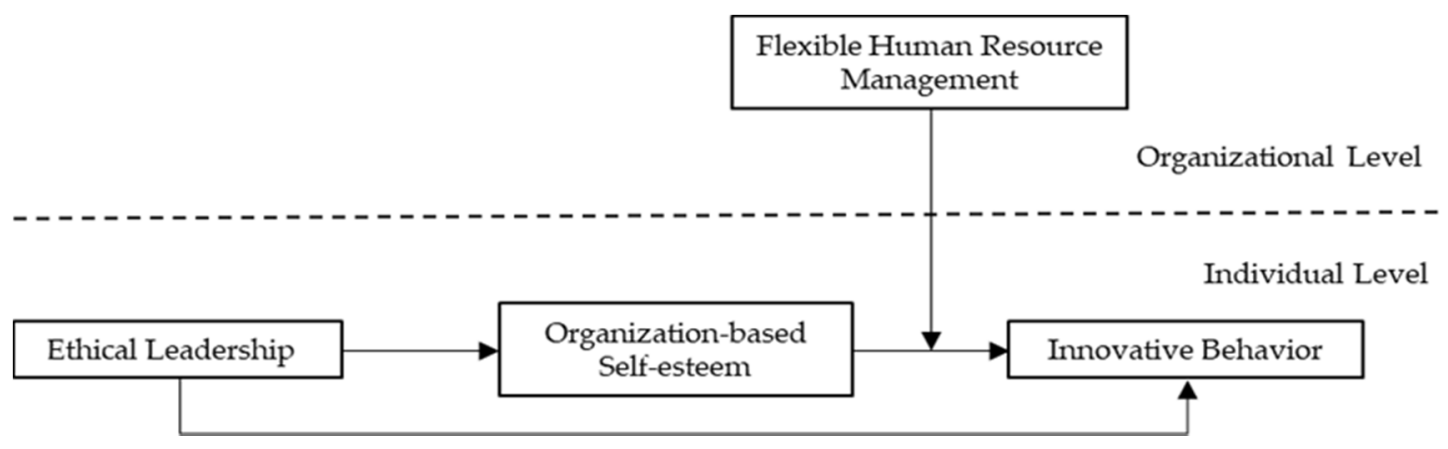

Figure 1. Research Model.

\section{Methodology}

\subsection{Sample and Data Collection}

The questionnaire data were collected from enterprises in Jiangsu, Shandong, Gansu, Guangdong and other places in China, involving education, manufacturing, finance, communication and other industries. Following Collins and Smith [55], we asked human resource managers of participating firms to randomly select a list of 3-10 core knowledge employees from their research and development (R\&D) departments, because core knowledge employees are the most important and meaningful group for innovation. To avoid common method bias, data were collected by supervisor-subordinate pairing mode and multiple sources. The survey was conducted in two phases, commencing in November 2019 and ending in February 2020. At phase 1, we distributed questionnaires to $500 \mathrm{em}$ ployees to survey their evaluation of ethical leadership, organization-based self-esteem and demographics information. Among them, 453 valid questionnaires were collected. Three months later, at phase 2 , we surveyed the 453 respondents on their innovative behavior, and asked the 453 responding employees' supervisors to assess FHRM at the organizational level. The questionnaire was filled in anonymously, and the number was set to complete the two-phase matching. The completed questionnaire was sealed and collected by specialized personnel on the spot. In addition, to encourage participation, we provided each respondent with a USB disk as a gift.

The survey initially involved 180 supervisors and 500 subordinates, following Luo and Jiang [56]. The invalid ones were deleted due to missing data or data mismatch 
between the two phases. Specifically, 34 supervisor cases and 135 subordinate cases were excluded due to issues with nonsampling error [57], and 146 supervisor questionnaires and 365 subordinate questionnaires were finally collected. In the employees' sample, male employees $(N=221)$ accounted for $60.55 \%$. Employees under the age of 30 accounted for $32.6 \%$, followed by those aged 30-39 (41.92\%), and employees over 40 (25.48\%), with an average age of 33.87 years $(\mathrm{SD}=7.59)$. The education level was mainly concentrated in high school, junior college, and university $(N=315,86.3 \%)$, and the average working tenure of employees was 6.62 years $(S D=5.66)$.

\subsection{Variables Measurement}

Except for the Chinese revision of the employees' innovative behavior questionnaire by Cao Yong and Xiang Yang [58], other key variables were measured by mature English scales, and the accuracy of the questionnaire was improved by a translation-back translation procedure [59]. All participants responded to a five-point Likert scale, ranging from 1 "totally disagree" to 5 "completely agree".

Ethical Leadership: Employees rated their ethical leaders according to Brown et al.'s 10-item ethical leadership measure [8]. Specific items included the following: "My leader listens to employees' opinions" and "My leader punishes employees who violate moral standards". The internal consistency Cronbach's $\alpha$ coefficient in this study was 0.915.

Organization-Based Self-Esteem: Pierce and Gardner's (2004) [43] 10-item scale was used to measure employees' self-evaluation of their own value and competence in the organization. Employees rated items such as "People around me think I am influential" and "I am valuable". The internal consistency Cronbach's $\alpha$ coefficient of the scale was 0.882.

Flexible Human Resource Management: Supervisors rated organizations' flexible human resource management using the 4-item scale from Sekhar et al. (2018) [60]. The representative items included the following: "We often change our HR practices to keep the HR system in line with changing job requirements" and "In general, our HR practices are flexible". The internal consistency Cronbach's $\alpha$ coefficient of the scale was 0.801 .

Innovative Behavior: On the basis of previous studies, this study adopted a 4-item scale evaluated by Cao and Xiang [58] that was a modified version of the scale provided by Scott and Bruce (1994) [29]. Specific items included the following: "I often generate innovative ideas in my work" and "I often seek new ways to improve my current work". The internal consistency Cronbach's $\alpha$ coefficient of the scale was 0.851 .

Control Variables: In the present research, we recorded the participants' gender, age and education levels as control variables [61]. Meanwhile, we also controlled the tenure of employees due to its significant impact on managers and employees' work behavior. Among them, gender was a dummy coded as $1=$ male, $0=$ female; in the age variables, " 1 " indicated participants under 25 years old, " 2 " indicated participants who were 25-30 years old, "3" 30-35 years old, " 4 " 34-40 years old, and " 5 " 40 years old and above; education level, the "junior high school and below", "senior high school", "junior college", "undergraduate", "graduate and above" were assigned to 1-5.

\subsection{Analysis Method}

This study aimed to test each hypothesis through the following steps: (1) For variables at different levels, confirmatory factor analysis (CFA) was used to investigate the discriminant validity and measurement parameters between constructs; (2) Descriptive statistics and correlation analysis were performed to make a preliminary judgment on the research model; (3) The main measurement variables of this study involved individual and organizational levels. Among them, FHRM is an organizational level variable evaluated by leaders, which cannot be aggregated. Individual level variables included ethical leadership, organization-based self-esteem and employees' innovation behavior. Therefore, this study uses the two-level path analysis method of moderated mediation to test the research hypothesis [62]. In this part, we mainly used Mplus7.0 and R software for data analysis. 


\section{Results}

\subsection{Confirmatory Factor Analyses (CFA)}

Table 1 reports the results of CFA and Chi-square difference tests. As shown in Table 1, the CFA results indicate that our hypothesized four-factor model (ethical leadership, organization-based self-esteem, flexible human resource management, employees innovative behavior $)$ is a better fit to the data $(\chi 2=731.450$; CFI $=0.922$; TLI $=0.906$; RMSEA $=0.060$; SRMR $=0.061$ ) than other parsimonious models, given that the Chi-square difference test results are all significant at the 0.001 level [63]. Based on this analysis, the discriminant validity of the four key variables is good enough for subsequent research.

Table 1. Confirmatory Factor Analyses (CFA) and Chi-square difference test results.

\begin{tabular}{cccccccc}
\hline Model & $\chi^{\mathbf{2}}$ & $\mathbf{d f}$ & $\chi^{\mathbf{2} / \mathbf{d f}}$ & $\mathbf{R M S E A}$ & TLI & CFI & SRMR \\
\hline Four-factor & 731.450 & 315 & 2.322 & 0.060 & 0.906 & 0.922 & 0.061 \\
Three-factor & 1361.489 & 318 & 4.281 & 0.095 & 0.767 & 0.804 & 0.137 \\
Two-factor & 1825.180 & 320 & 5.704 & 0.114 & 0.666 & 0.717 & 0.146 \\
One-factor & 2277.827 & 321 & 7.096 & 0.129 & 0.567 & 0.632 & 0.150 \\
\hline
\end{tabular}

Note: EL = Ethical Leadership, OBSE = Organization-based Self-esteem, FHRM = Flexible Human Resource Management, EIB = Employees' Innovative Behavior. Four-factor: EL, OBSE, FHRM, EIB; Three-factor: EL + OBSE, FHRM, EIB; Two-factor: EL + OBSE + FHRM, EIB; One-factor: EL + OBSE + FHRM + EIB.

\subsection{Correlation Analysis}

Table 2 presents the means, standard deviations and correlations of the variables in our model. As shown in Table 2, ethical leadership is positively correlated with OBSE $(r=0.350, p<0.01)$ and employees' innovative behavior $(r=0.263, p<0.01)$. OBSE is positively correlated with employees' innovation behavior $(\mathrm{r}=0.561, p<0.01)$, and thus $\mathrm{H} 1, \mathrm{H} 2$ and $\mathrm{H} 3$ were preliminarily verified.

Table 2. Means, standard deviations and correlations among key variables.

\begin{tabular}{|c|c|c|c|c|c|c|c|c|}
\hline Variable & 1 & 2 & 3 & 4 & 5 & 6 & 7 & 8 \\
\hline 1. Gender & - & & & & & & & \\
\hline 2. Age & $-0.145^{* *}$ & - & & & & & & \\
\hline 3. Education & 0.097 & $-0.293^{* * *}$ & - & & & & & \\
\hline 4. Work tenure & -0.044 & $0.587^{* *}$ & -0.038 & - & & & & \\
\hline 5. EL & -0.003 & -0.018 & 0.055 & -0.001 & & & & \\
\hline 6. OBSE & -0.038 & -0.028 & 0.030 & 0.019 & $0.350 * *$ & & & \\
\hline 7. EIB & -0.042 & 0.000 & 0.068 * & 0.017 & $0.263^{* *}$ & $0.561^{* *}$ & & \\
\hline 8. FHRM & -0.038 & -0.085 & -0.028 & -0.072 & 0.046 & $0.118^{*}$ & $0.143^{* *}$ & \\
\hline Mean & 1.397 & 33.874 & 2.679 & 6.623 & 3.918 & 3.758 & 3.501 & 3.697 \\
\hline S.D. & 0.501 & 7.593 & 1.040 & 5.663 & 0.739 & 0.640 & 0.763 & 0.791 \\
\hline
\end{tabular}

Note: ${ }^{*} p<0.05 ;{ }^{* *} p<0.01 ;{ }^{* * *} p<0.001$. EL = Ethical Leadership, OBSE = Organization-based Self-esteem, FHRM = Flexible Human Resource Management, EIB = Employees' Innovative Behavior.

\subsection{Hypotheses Testing}

Given that this study involves individual and organizational levels, before the statistical analysis of data we had to calculate the relevant indicators of employees' innovative behavior to examine the differences between groups. We adopted the common indices ICC and Rwg for the test [64,65]. Specifically, the ICC (1), ICC (2) and Rwg for employees' innovative behavior were $0.585,0.849$ and 0.846 , respectively. These statistics indicate the necessity of using the cross-hierarchy analysis strategy [66].

Using Mplus7.0, a multi-level linear model (MLM) was constructed to test the proposed model. The results of all the path coefficients are presented in Figure 2. The hypothesized path between ethical leadership and employees' innovative behavior is significant $(\gamma=0.078, p<0.05)$, thus H1 is supported; The hypothesized path between ethical leadership and organization-based self-esteem is significant $(\gamma=0.182, p<0.05)$, 
and the relationship between OBSE and employees' innovative behavior is also significant $(\gamma=0.526, p<0.01)$. Hence, $\mathrm{H} 2$ and $\mathrm{H} 3$ are verified. Furthermore, we incorporated ethical leadership and OBSE into the model, the mediating variable OBSE remained significant $(\gamma=0.407, p<0.05)$, and H4 is supported. In addition, FHRM exhibited a significant positive moderating role in the relationship between OBSE and employees' innovative behavior $(\gamma=0.152, p<0.01)$ - that is, H5 is supported.

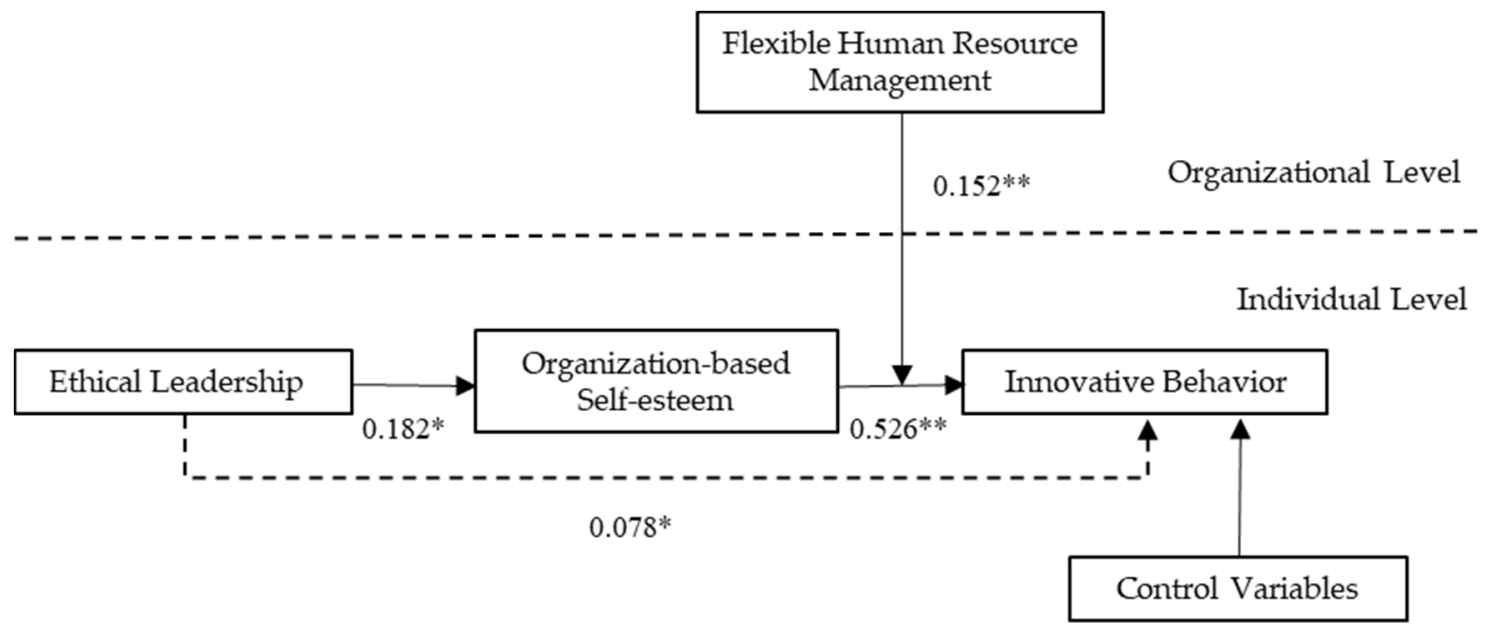

Figure 2. MLM path analysis diagram. Note: ${ }^{*} p<0.05 ;{ }^{* *} p<0.01$.

As suggested by Cohen et al. [67], this study constructs the interaction diagram of moderation effect under different levels of FHRM (see Figure 3). When the FHRM is at a high level, the positive effect of OBSE on employees' innovative behavior is significant $\left(\gamma_{1}=0.429, p<0.01\right)$. When the FHRM is at a low level, OBSE still positively affected employees' innovative behavior, but the result is not significant $\left(\gamma_{2}=0.043, p>0.05\right)$, which further verifies H5. Next, R software was used to test the significance of the mediation effect of OBSE between ethical leadership and EIB at different levels of FHRM through the bootstrapping method [61], and the results are shown in Table 3. When the FHRM is at a high level, the indirect effect of ethical leadership on EIB through OBSE is $0.344(p<0.001)$. When the FHRM is at a relatively low level, the indirect effect is $0.140(p<0.05)$, and the two indirect effects of estimated results are significant differences $(\Delta=0.204, p<0.05)$. Therefore, the indirect effect of ethical leadership on employees' innovative behavior is moderated by FHRM, and the higher the level of FHRM, the stronger the indirect effect. Hence, $\mathrm{H} 6$ is supported.

Table 3. Moderated mediation effect test.

\begin{tabular}{cccccc}
\hline & FHRM & Effect Value & Standard Error & Lower Limit & Upper Limit \\
\hline \multirow{2}{*}{ Indirect } & High level & 0.344 & 0.082 & 0.134 & 0.555 \\
Effect & Low level & 0.140 & 0.069 & 0.027 & 0.317 \\
& $\Delta$ & 0.204 & 0.076 & 0.080 & 0.399 \\
\hline
\end{tabular}




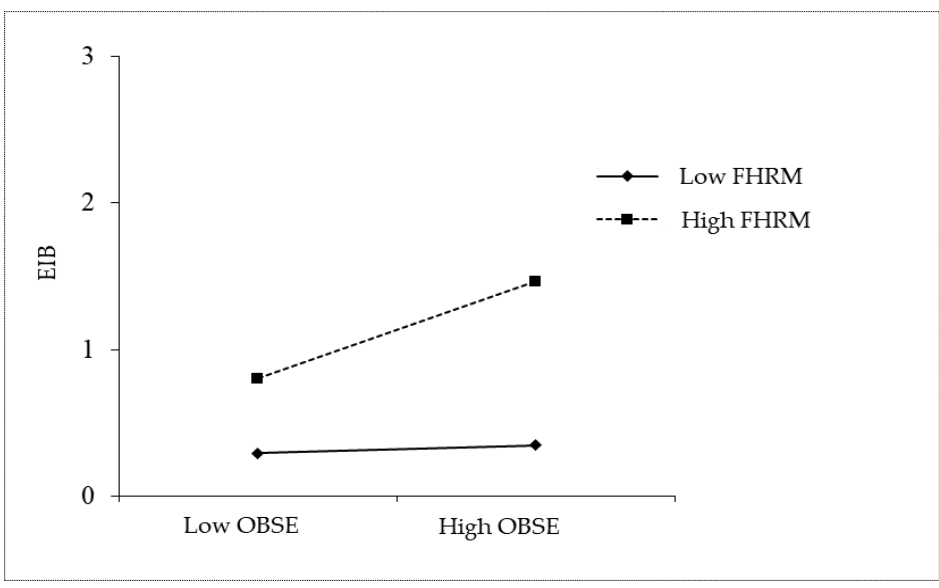

Figure 3. The moderating effect of FHRM on the relationship between OBSE and EIB. Note: FHRM = Flexible Human Resource Management, OBSE = Organization-based Self-esteem, EIB = Employees' Innovative Behavior.

\section{Discussion}

This study explored the internal mechanism and boundary conditions between ethical leadership and employees' innovative behavior through a multi-level linear model. Specifically, the results of our study showed that ethical leadership enhanced employees' innovative behavior. We theorized and empirically validated that organization-based selfesteem (OBSE) plays a partial mediating role between ethical leadership and employees' innovative behavior. Ethical leadership positively impacts employees' innovative behavior, which is partly due to the various kinds of support provided by ethical leadership, that makes employees feel important and valuable to the organization, stimulate employees to have high level of OBSE, and thus encourage them to adopt innovative behaviors that are beneficial to the organization. Moreover, we confirmed that flexible human resource management (FHRM) plays a cross-level moderating role in the relationship between OBSE and employees' innovative behavior and the indirect effect of ethical leadership on employees' innovative behavior through OBSE. Moreover, compared with organizations with low FHRM, organizations with high FHRM have a strong positive correlation between employees' OBSE and their innovative behavior, and ethical leadership has a strong influence on employees' innovative behavior through OBSE. The following sections will focus on the theoretical and practical implications of this research, discuss the limitations of our work and propose future research directions.

\subsection{Theoretical Implications}

Our research contributes to the literature in the following ways. First, this study expands the internal mechanism of ethical leadership on employees' innovative behavior. In previous studies, scholars verified the transfer effects of employees' intrinsic motivation, psychological capital, psychological security and knowledge sharing through relevant empirical studies. From the perspective of individual self-concept based on a group, this study explains the mediating variable of ethical leadership influencing employees' innovative behavior and organization-based self-esteem and verifies its transmission effect. This study also provides a new explanation path for the influence of ethical leadership on employees' innovative behavior, which responds well to the call of the existing studies [13] to strengthen the psychological mechanism of ethical leadership influencing employee behavior.

Second, the present study demonstrated the role of FHRM as a boundary condition, which helps understand the influence of the organizational context on the formation process of employees' innovative behavior and broadens the boundary conditions of the influence of ethical leadership on employees' innovative behavior. This research shows that a flexible 
human resource management environment promotes the formation of innovative behavior on the part of employees. Thus, the more FHRM-conducive a system environment is, the more it will meet the needs of employees for flexible work arrangements and provide them with the required resources. In this situation, employees will be willing to work and simultaneously perceive their importance in the organization, thereby making substantial innovative behavior.

Third, this study also contributes to the research on FHRM. Currently, most studies on FHRM are designed with independent or intermediary variables. For example, Chang et al. [51] present a theoretical explanation of how FHRM systems may influence market responsiveness and firm innovativeness through the lens of absorptive capacity. Ketkar and Sett [68] conducted research on Indian manufacturing and service companies and found that FHRM has an intermediary role in the relationship between environmental dynamics and organizational performance. This study takes it as a moderating effect on the relationship between organization-based self-esteem and employees' innovative behavior and the indirect effect of ethical leadership on employees' innovative behavior through organization-based self-esteem, which expands the theoretical research on FHRM, thus deepening our understanding of FHRM.

\subsection{Practical Implications}

These results have several significant practical implications for enterprises. First, ethical leadership is found to positively influence employees' innovative behavior, a result that suggests that enterprises should recognize that ethical leadership is beneficial to their long-term development and should strengthen the cultivation of ethical leadership. In addition to the requirements of professional skills, enterprises should also focus on ethics and moral cultivation when selecting managers, so that they will respect and support their subordinates and give them work autonomy, and so that the enterprise can acquire a positive ethical culture atmosphere, thereby laying the foundations for the promotion of employees' innovative behavior.

Second, organization-based self-esteem mediates the relationship between ethical leadership and employees' innovative behavior, so it is necessary for managers to pay attention to employees' organization-based self-esteem. The higher an employee's organizationbased self-esteem is, the more likely they are to engage in innovative behavior. Therefore, managers can promote employees' organization-based self-esteem by respecting their opinions, expressing recognition and respect to them, caring for employees, focusing on authorization, encouraging them to participate in decision-making work and creating a fair competitive atmosphere in order to stimulate more innovative behaviors.

Third, our results reveal that flexible human resource management has a positive moderating effect on the relationship between organization-based self-esteem and employees innovative behavior and the indirect effect of ethical leadership on employees' innovative behavior through organization-based self-esteem. This illustrates that the management system adopted by an organization will influence the impact of the leadership style on its employees' innovative behavior. Therefore, with the increasingly fierce competition and uncertainty, enterprises should not only focus on the importance of the leadership, but also understand the importance of their flexible human management system, which can not only improve the demand of employees for work flexibility but also increase their willingness to work, so that employees can actively pursue innovative activities in a flexible and relaxed working environment, and then promote the improvement of enterprise innovation and gain competitive advantages for enterprises.

\subsection{Limitations and Future Research Directions}

This research has several limitations, which suggest meaningful future research directions. First, although we adopt two stages and paired tracking to collect data, most of the data are from employees' self-evaluation, especially employees' innovative behavior, and hence homologous errors are to some extent unavoidable. Therefore, a rigorous research 
design could be considered in future research to improve the accuracy and external validity of the conclusions. Meanwhile, we only collected data from a single source of questionnaire, but future research can adopt significantly different methods (e.g., the collection of objective quantitative data, the results from an additional experimental study, longitudinal observations, qualitative findings, etc.) to avoid the single-source bias issue, or monitor some variables over time to make the study longitudinal and significantly strengthen the findings. Second, this research only considers the impact of direct supervisors on employees' innovative behavior. However, relevant studies show that different levels of leadership have distinct influences on employees. In the future, we can further explore the influence mechanism of ethical leadership at different levels on employees' innovative behavior. Third, our data was collected in a Chinese context, which is influenced by traditional Chinese culture. Different views on ethical leadership research may be found in other contexts. Therefore, future research may conduct investigations in other regions and countries to verify the results of this study. Finally, we explain the relationship between ethical leadership and employees' innovative behavior from the perspective of organization-based self-esteem of self-concept, while perceived insider status, another aspect of self-concept, remains unincluded. In future research, we can construct, verify and interpret the two constructs as a whole, or introduce new mediating variables from other theoretical perspectives, such as self-efficacy and personality, to explore the influence mechanism of ethical leadership on employees' innovative behavior.

\subsection{Conclusions}

In conclusion, the results of this study indicate that ethical leadership positively predicts employees' organization-based self-esteem, which has a positive impact on employees' innovative behavior, and the flexible human resource management of the organization has a positive moderate effect on the relationship between organization-based self-esteem and employees' innovative behavior. These results show not only that leadership plays a positive role in promoting employee innovation, but also that flexible human resource management enables employees to effectively develop their abilities and promote them to pursue more innovative behaviors.

Author Contributions: Conceptualization, Q.W. and J.L.; methodology, Q.W. and Y.W.; software, Q.W.; investigation, Q.W. and J.L.; data curation, Q.W. and J.L.; writing-original draft preparation, Q.W. and Y.W.; writing-review and editing, J.L. and Y.W.; supervision, J.L. All authors have read and agreed to the published version of the manuscript.

Funding: This study was funded by the National Natural Science Foundation of China (grant number: 71672080).

Institutional Review Board Statement: Institutional Review Board Statement is not required for this paper in China.

Informed Consent Statement: Informed consent was obtained from all subjects involved in the study.

Data Availability Statement: The dataset generated and analyzed in this study is not publicly available. Dataset is available from the corresponding author on reasonable request.

Conflicts of Interest: The authors declare no conflict of interest.

\section{References}

1. Liu, Y.; Qu, R.J.; Shi, K.; Deng, M.C. Leader creativity expectations and employee radical creativity: A creative process engagement perspective. Nankai Bus. Rev. 2016, 6, 17-26.

2. $\quad$ Pieterse, A.N.; Knippenberg, D.V.; Schippers, M.; Stam, D. Transformational and transactional leadership and innovative behavior: The moderating role of psychological empowerment. J. Organ. Behav. 2009, 31, 609-623. [CrossRef]

3. Xu, S.Y.; Zhang, B.N.; Liu, Y.J.; Xu, F.F.; Wang, J.X. The impact of affective leadership on co-worker relationship closeness and employee innovative behavior: A moderated mediation model. Sci. Technol. Prog. Policy 2019, 20, 134-143.

4. Young, L.D. How to promote innovative behavior at work? The role of justice and support within organizations. J. Creat. Behav. 2012, 46, 220-243. [CrossRef] 
5. Nazir, S.; Qun, W.; Hui, L.; Shafi, A. Influence of social exchange relationships on affective commitment and innovative behavior: Role of perceived organizational support. Sustainability 2018, 10, 4418. [CrossRef]

6. Li, H.; Sajjad, N.; Wang, Q.; Muhammad, A.A.; Khaqan, Z.; Amina, S. Influence of transformational leadership on employees' innovative work behavior in sustainable organizations: Test of mediation and moderation processes. Sustainability 2019, $11,1594$. [CrossRef]

7. Han, Y.; Yang, B.Y. The authentic leadership, the psychological capital and employees' innovative behavior: The mediating of the leading members. Manag. World 2011, 12, 78-86.

8. Brown, M.E.; Trevino, L.K. Ethical leadership: A review and further directions. Leadersh. Q. 2006, 17, 595-616. [CrossRef]

9. Lu, X.J. Ethical leadership and organizational citizenship behavior: The mediating roles of cognitive and affective trust. Soc. Behav. Personal. Int. J. 2014, 42, 379-389. [CrossRef]

10. Fan, H.; Zhou, Z.C. Moral identity and ethical leadership: A mediated moderating model. Ind. Eng. Manag. 2017, 22, 125-131.

11. Zhang, Y.J. The influence of ethical leadership on employees' CWB: Test the mediating effect of organization-based self-esteem. Chin. J. Manag. Sci. 2015, S1, 645-649.

12. Avey, J.B.; Palanski, M.E.; Walumbwa, F.O. When leadership goes unnoticed: The moderating role of follower self-esteem on the relationship between ethical leadership and follower behavior. J. Bus. Ethics 2011, 98, 573-582. [CrossRef]

13. Tu, Y.D.; Lu, X.X. How ethical leadership influence employees' innovation work behavior: A perspective of intrinsic motivation. J. Bus. Ethics 2013, 116, 441-455. [CrossRef]

14. Wang, Z.C.; Yang, J.F. Research on the relationship among ethical leadership, psychological safety and employees' innovative behavior. Dongyue. R. 2018, 8, 118-125.

15. Chen, A.S.; Hou, Y.H. The effects of ethical leadership, voice behavior and climates for innovation on creativity: A moderated mediation examination. Leadersh. Q. 2016, 27, 1-13. [CrossRef]

16. Zhu, W.C.; May, D.R.; Avolio, B.J. The impact of ethical leadership behavior on employee outcomes: The roles of psychological empowerment and authenticity. J. Leadersh. Organ. Stud. 2004, 11, 16-26.

17. Haq, M.; Davies, J. "The person with maximum knowledge will win the race": Conceptualizing knowledge in microbusinesses. J. Small Bus. Manag. 2020, 8, 1-27. [CrossRef]

18. Zhang, Y.J. The influence of ethical leadership on employees' CWB: From social learning and social exchange perspective. J. Bus. Econ. 2012, 12, 23-32.

19. Xiao, G.R.; Zhao, Y.J. Ethical leadership and employees' turnover intention: Leader-member exchange as a mediator. Sci. Sci. Manag. S. T 2017, 38, 160-171.

20. Sitzmann, T.; Ployhart, R.E.; Kim, Y. A process model linking occupational strength to attitudes and behaviors: The explanatory role of occupational personality heterogeneity. J. Appl. Psychol. 2019, 104, 247-269. [CrossRef]

21. $\mathrm{Wu}, \mathrm{J}$. Decent labor, organizational self-esteem and employee innovative behavior: From the perspective of labor rights protection and organizational innovation award. Forecasting 2019, 6, 39-44.

22. Zheng, X.Y.; Li, Y.P.; Liu, Z.H. The impact of knowledge sharing on employees' innovative behavior: The role of organizationbased self-esteem and perceived organizational support. J. Bus. Econ. 2017, 1, 24-33.

23. Esfahani, S.A.; Rezaii, H.; Koochmeshki, N.; Parsa, S.S. Sustainable and flexible human resource management for innovative organizations. AD Minist. 2017, 30, 195-215. [CrossRef]

24. Crane, A.; Matten, D.; Glozer, S.; Spence, L. Business Ethics: Managing Corporate Citizenship and Sustainability in the Age of Globalization; Oxford University Press: Oxford, UK, 2019.

25. Fahri, Ö. The impact of ethical leadership on service innovation behavior: The mediating role of psychological capital. Asia Pac. J. Manag. 2019, 13, 3-18.

26. Hansen, S.; Alge, B.; Brown, M.; Jackson, C.; Dunford, B. Ethical leadership: Assessing the value of a multifoci social exchange perspective. J. Bus. Ethics 2013, 115, 435-449. [CrossRef]

27. Lu, X.J.; Guy, M.E. How emotional labor and ethical leadership affect job engagement for Chinese public servants. Public Pers. Manag. 2014, 43, 3-24. [CrossRef]

28. Kalshoven, K.; Den Hartog, D.N.; De Hoogh, A.H.B. Ethical leadership at work questionnaire(ELW): Development and validation of a multidimensional measure. Leadersh. Q. 2011, 22, 51-69. [CrossRef]

29. Scott, S.G.; Bruce, R.A. Determinants of innovative behavior: A path model of individual innovation in the workplace. Acad. Manag. J. 1994, 37, 580-607.

30. Kanter, R.M. When a thousand flowers bloom: Structural, collective, and social conditions for innovation in organizations. Knowl. Manag. Organ. Des. 1988, 10, 93-131.

31. Kuvaas, B.; Buch, R.; Dysvik, A.; Haerem, T. Economic and social leader-member exchange relationships and follower performance. Leadersh. Q. 2012, 23, 756-765. [CrossRef]

32. Tian, M.; Deng, P.; Zhang, Y.; Salmador, M.P. How does culture influence innovation? A systematic literature review. Manag. Decis. 2018, 5, 1088-1107. [CrossRef]

33. Ren, F.; Zhang, J. Job stressors, organizational innovation climate, and employees' innovative behavior. Creat. Res. J. 2015, 27, 16-23. [CrossRef]

34. Wang, S.Y.; Liu, H.; Lin, Y.M. How does family supportive leadership affect employee's innovative behavior: The chain mediation effects of self-concept. Sci. Sci. Manag. S. T 2019, 3, 99-115. 
35. De Hoogh, A.H.B.; Den Hartog, D.N. Ethical and despotic leadership, relationships with leader's social responsibility, top management team effectiveness and subordinates' optimism: A multi-method study. Leadersh. Q. 2008, 19, 297-311. [CrossRef]

36. Piccolo, R.F.; Greenbaum, R.; Hartog, D.N.D.; Folger, R. The relationship between ethical leadership and core job characteristics. J. Organ. Behav. 2010, 31, 259-278. [CrossRef]

37. George, J.M. Creativity in organizations. Acad. Manag. Ann. 2007, 1, 439-477. [CrossRef]

38. Liao, P.Y. The role of self-concept in the mechanism linking proactive personality to employee work outcomes. J. Appl. Psychol. 2015, 64, 421-443. [CrossRef]

39. Chen, Z.X.; Aryee, S. Delegation and employee work outcomes: An examination of the cultural context of mediating processes in China. Acad. Manag. J. 2007, 50, 226-238. [CrossRef]

40. Coopersmith, S. The Antecedents of Self-Esteem; Freeman: San Francisco, CA, USA, 1967.

41. Pierce, J.L.; Gardner, D.G.; Cummings, L.L.; Dunham, R.B. Organization-based self-esteem: Construct definition measurement and validation. Acad. Manag. J. 1989, 32, 622-648.

42. Lu, X.X.; Tu, Y.D. Contextualization and generalizability of organization-based self-esteem. Adv. Psychol. Sci. 2014, 22, 130-138. [CrossRef]

43. Pierce, J.L.; Gardner, D.G. Self-esteem within the work and organizational context: A review of the organization-based self-esteem literature. J. Manag. 2004, 30, 591-622. [CrossRef]

44. Lin, N.; Jang, J.; Roberts, K.R. Are employees with higher organization-based self-esteem less likely to quit? A moderated mediation model. Int. J. Hosp. Manag. 2018, 73, 116-124. [CrossRef]

45. Bowling, N.A.; Eschleman, K.J.; Wang, Q.; Kirkendall, C.; Alarcon, G. A meta-analysis of the predictors and consequences of organization based self-esteem. J. Occup. Organ. Psychol. 2010, 83, 601-626. [CrossRef]

46. Hu, W.W.; Ding, Y.Z.; Luo, J.; Wang, X.Y.; Zhu, Z.L. A research on the relationship among idiosyncratic deal, organization-based self-esteem and knowledge sharing behavior. Sci. Res. Manag. 2018, 4, 134-143.

47. Rank, J.; Nelson, N.E.; Allen, T.D. Leadership predictors of innovation and task performance: Subordinates' self-esteem and self-presentation as moderators. J. Occup. Organ. Psychol. 2009, 82, 465-489. [CrossRef]

48. Bal, P.M.; De Lange, A.H. From flexibility human resource management to employee engagement and perceived job performance across the lifespan: A multisample study. J. Occup. Organ. Psychol. 2015, 88, 126-154. [CrossRef]

49. Cordery, J.; Sevastos, P.; Mueller, W.; Parker, S. Correlates of employee attitudes toward functional flexibility. Hum. Relat. 1993, 46, 705-723. [CrossRef]

50. Peretz, H.; Fried, Y.; Levi, A. Flexible work arrangements, national culture, organisational characteristics, and organizational outcomes: A study across 21 countries. Hum. Resour. Manag. J. 2018, 28, 182-200. [CrossRef]

51. Chang, S.; Gong, Y.; Way, S.A.; Jia, L. Flexibility-oriented HRM systems, absorptive capacity, and market responsiveness and firm innovativeness. J. Manag. 2013, 39, 1924-1951. [CrossRef]

52. Zhang, M.M.; Bartram, T.; McNeil, N.; Dowling, P.J. Towards a research agenda on the sustainable and socially responsible management of agency workers through a flexicurity model of HRM. J. Bus. Ethics 2015, 127, 513-523. [CrossRef]

53. Li, Y.P.; Zheng, X.Y.; Liu, Z.H. The effect of perceived insider status on employee voice behavior: A study from the perspective of conservation of resource theory. Chin. J. Manag. 2017, 14, 196-204.

54. Allen, T.D.; Johnson, R.C.; Kiburz, K.M.; Shockley, K.M. Work-family conflict and flexible work arrangements: Deconstructing flexibility. Pers. Psychol. 2013, 66, 345-376. [CrossRef]

55. Collins, C.J.; Smith, K.G. Knowledge exchange and combination: The role of human resource practices in the performance of high-technology firms. Acad. Manag. J. 2006, 49, 544-560. [CrossRef]

56. Luo, S.Q.; Jiang, Y. Management Survey Research Methodology; Chongqing University: Chongqing, China, 2014 ; pp. 127-159.

57. Blair, J.; Czaja, R.F.; Blair, E.A. Designing Surveys: A Guide to Decisions and Procedures; Sage Publications: Thousand Oaks, CA, USA, 2013.

58. Cao, Y.; Xiang, Y. Study on the relationship among knowledge governance, knowledge sharing and employee innovation based on the mediating of social capital and the moderating of absorptive capacity in enterprises. Stud. Sci. Sci. 2014, 32, 92-102.

59. Brislin, R.W. Back-translation for cross-cultural research. J. Cross Cult. Psychol. 1970, 1, 185-216. [CrossRef]

60. Sekhar, C.; Patwardhan, M.; Vyas, V. Linking work engagement to job performance through flexible human resource management. Adv. Dev. Hum. Resour. 2018, 20, 72-87. [CrossRef]

61. Li, R.; Ling, W.S.; Liu, S.S. Traditional values, superior subordinate relationship and employee silence behavior: An empirical study in the context of local culture. Manag. World 2012, 3, 127-140.

62. Chen, X.P.; Xu, S.Y.; Fan, J.L. Empirical Methods for Organizational Management Research; Peking University: Beijing, China, 2012; pp. 545-579.

63. Fornell, C.; Larcker, D.F. Evaluating structural equation models with unobservable variables and measurement error. J. Mark. Res. 1981, 18, 39-50. [CrossRef]

64. Bliese, P.D. Within-Group Agreement, Non-Independence, and Reliability: Implications for Data Aggregation and Analysis; Jossey-Bass: San Francisco, CA, USA, 2000; pp. 349-381.

65. James, L.R.; Demaree, R.G.; Wolf, G. Estimating within-group interrater reliability with and without response bias. J. Appl. Psychol. 1984, 69, 85-98. [CrossRef] 
66. Zhang, J.W.; Long, L.R. The gap effects of different level high-performance work systems: A moderated mediation model. Nankai Bus. Rev. 2017, 20, 180-190.

67. Cohen, J.; Cohen, P.; West, S.G.; Aiken, L.S. Applied Multiple Regression/Correlation Analysis for the Behavioral Sciences; Lawrence Erlbaum Associates: Mahwah, NJ, USA, 2013.

68. Ketkar, S.; Sett, P.K. Environmental dynamism, human resource flexibility, and firm performance: Analysis of a multi-level causal model. Int. J. Hum. Resour. Manag. 2010, 21, 1173-1206. [CrossRef] 